\title{
EUROSDR GEOBIM PROJECT A STUDY IN EUROPE ON HOW TO USE THE POTENTIALS OF BIM AND GEO DATA IN PRACTICE
}

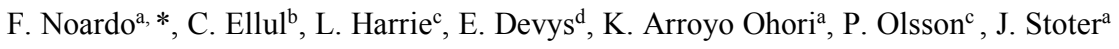 \\ a 3D Geoinformation research group, Delft University of Technology, Delft, The Netherlands - [ F.Noardo | J.E.Stoter | \\ K.ArroyoOhori]@tudelft.nl \\ ${ }^{\mathrm{b}}$ Dept. of Geomatic Engineering, University College London, Gower Street, London, WC1E 6BT UK - c.ellul@ucl.ac.uk \\ ${ }^{\mathrm{c}}$ Department of Physical Geography, Lund University, Lund, Sweden - [lars.harrie | perola.olsson]@nateko.lu.se \\ d IGN Institut géographique national, France - Emmanuel.Devys@ign.fr
}

KEY WORDS: GeoBIM, software support, data interoperability, open standards, 3D city models, BIM

\begin{abstract}
:
In both the Geo and BIM domains, it is widely acknowledged that the integration of geo-data and BIM-data is beneficial and a crucial step in facing the multi-disciplinary challenges of our built environment. The result of this integration - broadly termed as GeoBIM - has a range of potential uses from district study to road safety. However, from the data perspective, this integration raises the question of how to integrate very detailed design and construction data from the BIM domain with contextual geospatial data (both 2D and 3D) that model a very diverse range of aspects of the wider built and natural environment.

This paper reports work carried out during the second phase of the EuroSDR GeoBIM project, which sets out to understand the general status of GeoBIM across Europe with particular focus from a National Mapping and Cadastral Agency perspective. The first phase of the project reviewed the current status of GeoBIM in participating countries and identified the need for specific detailed use cases to overcome both the lack of awareness and the lack of understanding of the potential of GeoBIM. We present both an update on the current status of GeoBIM, and additional details of one of the selected use cases relating to planning/development permits. For the latter, we have been able to develop a detailed workflow highlighting specific data exchange points within the process to issue a development permit, allowing a more in-depth identification of both the roles and data needs at each stage.
\end{abstract}

\section{INTRODUCTION}

In both the Geo and Building Information Modelling (BIM) domains, it is widely acknowledged that the integration of geo-data and BIM-data is beneficial and a crucial step in facing the multi-disciplinary challenges of our built environment. It could benefit application domains including city analysis and administration, architecture, construction and asset management. However, full integration of the geospatial and BIM domains would need to consider legal and procedural/operational issues, besides the more technical ones. In addition, the specific needs of the many stakeholders involved in design and construction cannot be disregarded.

The data component of this full integration raises the question of how to integrate very detailed design and construction data from the BIM domain with contextual geospatial data (both $2 \mathrm{D}$ and $3 \mathrm{D}$ ) that models a very diverse range of aspects of the wider built environment and also underpins analytical analysis. To address this issue at the multi-country level, twelve National Mapping and Cadastral Agencies (NMCAs) and five research groups in Europe started a collaboration under the flag of the organisation European Spatial Data Research (EuroSDR), to obtain understanding how the BIM domain can make better use of NMCA geo-data and vice versa.

The aim of the project is to detail both the needs and the issues of GeoBIM integration, studied in relation to use cases as well as from existing experiences in the participating countries, with the ultimate goal to increase the use of NMCA-data in the BIM domain and vice versa.

The first phase of the project (Ellul et al. 2018) reported the results of a survey conducted across the partner countries. It highlighted a number of general challenges and opportunities for GeoBIM - both technical and non-technical. It also reviewed the status of GeoBIM across the participating countries, highlighting that the level of GeoBIM maturity varied significantly from no or very few initiatives to mature projects. Results showed that at the time, none of the participating countries had national-level projects and that one of the major issues was a lack of understanding of what GeoBIM is and what it could offer.

To address this issue, the second phase of the EuroSDR project is developing two use cases, related to asset management (to be reported on later in the project) and planning/permit applications. This paper is split into two parts throughout. Each section first provides an update on general GeoBIM related activities performed across the partner NMCA countries, and then presents some of the work carried out towards the planning/permit applications use case.

* Corresponding author 


\section{BACKGROUND}

\subsection{Geospatial and BIM Integration}

Ellul et al. (2018) summarise key similarities (both model the built environment, both can model in $3 \mathrm{D}$, both use objectbased models) and differences (georeferencing is not at the core of BIM, geometry is modelled as boundary-representation for geospatial data but using mainly parametrically modelled solids for BIM, geospatial data is country-wide, BIM is sitespecific) between geospatial information and data from building information models, and highlight the challenges of integration. A more detailed comparison and review can be found in Liu et al. (2017) and Zhu et al. (2018). Additionally, Arroyo et al. (2018) note that general benefits of GeoBIM integration include the fact that with contextual GIS information, BIM methodologies can be better applied to infrastructural works; more detailed 3D city models can be built by reusing BIM data; smart city concept related tools can perform integrated reasoning making seamless use of data relating to terrain, buildings and city infrastructure; spatial analyses can be supported by multiple levels of detail and the complete life cycles of objects.

Additional examples of recent GeoBIM integration efforts from the literature include:

- Díaz-Vilariño et al. (2018) describe the use of a ScanToBIM approach that makes use of a travelling salesman approach to identify the optimal placement of laser scanning devices when using a stop-and-go approach to scanning. This is applied to a construction scenario to assess progress of the construction works.

- Hor et al. (2018) describe a Resource Description Framework and graph database approach to integrating Industry Foundation Classes and CityGML data into a seamless database. In particular, they propose that using this approach, coupled with conceptual integration defined by a semantic layer, the resulting data can be seamlessly queried, and will consist of objects from IFC, objects from CityGML and objects that integrate properties from both.

- Burry et al. (2018) identify an interim level between BIM and the wider context usually represented by geospatial data (in their terminology, City Information Modelling) precinct level modelling. They note some general issues relating to using BIM for this level of modelling, including: large file sizes that make collaboration difficult, a limited number of analytical tools, limited validation tools for use on a wide range of datasets and too much focus on geometry rather than spatial objects. The paper explores, in particular, the use of generative design at the precinct level, mentioning that subtractive solar amenity preservation tool called 'Subtracto-Sun' (White, 2010, cited in Burry et al., 2018) was used to inform volumetric building restriction (Burry et al., 2018).

- Arroyo et al., (2018) present the results of a series of GeoBIM experiments noting in particular that problems with the BIM geometry can cause issues when integrating with geospatial data. Recommendations include using georeferencing but also making use of specific rather than generic IFC object types and where possible making use of valid volumetric objects. IFC spaces are noted as important both for buildings but also as a potential approach to modelling geological data in BIM and hence in a geospatial environment (Arroyo et al., 2018).
- $\quad$ Sun et al. (2019) performed a study of using a GeoBIM approach for updating 3D city models. Currently, such models are often updated using Airborne Laser Scanning (ALS). However, because of the long ALS update cycle, building information models (BIM) could be utilized to maintain the models. In their study, they designed, implemented, and evaluated a methodology to formalize the integration of BIM data into city models. CityGML models were created from BIM data and ALS/footprint data based on common modelling guidelines. The relative differences between the models are on the order of decimetres.

\subsection{GeoBIM and Planning Permits}

In case of the building permit process there are several advantages given by a GeoBIM approach compared to the current situation, which, in most countries today, is based on $2 \mathrm{D}$ cross-section drawings (of the building) and a $2-2.5 \mathrm{D}$ situation plan (showing where the building is situated on a municipal map). There are several building regulations currently checked manually that could benefit a GeoBIM approach to enabling automation, e.g. dimensioning and spatial design, especially when the constraints relate to the existing context, where the building is designed, such as to other buildings, roads, and so on; energy related analysis and simulations; detailed noise modelling; air pollution simulations; escape routes planning, and more. Furthermore, automation would mean that the objectivity in the interpretation of regulations, by both the designer and the Municipality offices in charge of the building permit, would increase, with clear advantages for both parties.

Recent research efforts focussing on this domain echo these general principles. Oldfield et al. (2018) examine GeoBIM and planning in conjunction with cadastral requirements in the Netherlands and look specifically at how having a clearly specified Information Delivery Manual can help towards a full lifecycle electronic buildings dossier. As well as introducing the important concept of an 'As Sold' model (along with an 'As Permitted' and 'As Built' model) they present some preliminary use cases ('transaction maps') to give a high level overview of the process. While not going into specific detail of which constraints can be automatically validated, they mention soil pollution, easements, whether the building positioned within legal boundaries or zoned correctly as examples of the types of things that could be checked (Oldfield et al 2018).

Brasebin et al. (2017, 2017b) have investigated the potential of $3 \mathrm{D}$ information systems and topographic data to translate urban regulation into $3 \mathrm{D}$ geometries, properties or relationships and study the impact of a regulation in terms of possible new buildings in a given urban area.

Olsson et al. (2018) present a detailed case study focussing on the potential for GeoBIM when issuing permits in Sweden. They note in particular three types of rules that could be checked: quantitative (e.g. area, height), qualitative (e.g. does the building fit the surroundings, meet local architectural standards) and visual (e.g. do the windows meet certain characteristics). Three detailed examples are presented: building height, building footprint and area characteristics, and emphasized the importance of clarity of the rules (e.g. how is height measured/calculated) as fundamental to any automation process. The BIM itself should also be modelled 
following a specific quality standard (with outer walls flagged as such, and with information relating to slabs/foundations to enable area calculation). Potential users include applicants and municipalities (Olsson et al., 2018).

\section{METHOD}

Two components of the second phase of the EuroSDR GeoBIM study are presented here: firstly, an update on the status of GeoBIM amongst the participating countries; and secondly, progress on the planning/permits use case.

\subsection{GeoBIM Status Updates}

National updates of GeoBIM activities acrss Europe were captured via short presentations from each team member during the 6-monthly EuroSDR GeoBIM project meetings/workshops, supplemented by the completion of an online spreadsheet outlining the various initiatives identified.

\subsection{GeoBIM and Planning Permits}

Questions relating to this Use Case include:

1. What workflow should be followed for effectively using GeoBIM information for a Building Permission use case?

2. What are the regulations that can be (semi)automatically checked by a GeoBIM approach?

3. What are the related requirements for, and availability of, data for this automation (accuracy, semantics, topology, structure ect)?

To answer the questions, a series of round-table discussions were held where all 12 partner countries in the project got together to develop a general workflow for planning permit issuing that would apply across national borders (also based on discussions with plan checkers in each country), and then to refine this workflow through the addition of further details at each stage, with specific focus on the information required and the types of geospatial analysis that could usefully be undertaken to improve current practice at each stage. This second, much more detailed, workflow was again reviewed by the project partners and then a Use Case diagram (using UML notation) was developed to identify the different actors involved in the process.

To ensure validity the generated workflows were validated through consultation interviews with practitioners both in local municipalities (in the Netherlands) and in private practice (architects in Italy, the Netherlands, the UK).

\section{RESULTS}

Section 4.1 presents the results of the work that updated the inventory of GeoBIM activities across Europe and Section 4.2 presents the workflow that we designed for effectively using GeoBIM information for the Building Permission use case

\subsection{GeoBIM Status Updates}

Over the past year, there have been signs of increasing recognition of the term GeoBIM - with Google Scholar reporting 54 papers in 2017, 67 in 2018 and 31 to date in 2019 (3rd July 2019). A summary of the reported GeoBIM projects by participant country is given here, and includes information about general initiatives relating to the digitalisation of a planning/permit workflow.

4.1.1 The Netherlands In recent years, in the Netherlands, several initiatives are being developed to make use of integrated GeoBIM information. For example, the project "BIM verzamelen, verbinden en visualiseren voor vergunningverlening"2 (started in 2018), in which Municipalities (Rotterdam, Den Haag), designers and constructors (Studio Schaeffer, Dura Vermeer), research and service companies (TNO) participated, and investigated the use of BIM for building permission procedures. Moreover, an ongoing project "Digitale Stad en Omgevingswet" in the Rotterdam Municipality deals with the automation of building permit procedures, considering both BIMs and 3D city models.

Another project, "GeoBIM" (funded by RWS, BIM Loket, Kadaster, cities of The Hague and Rotterdam) was developed to work towards the integration of geoinformation (CityGML) with BIM. Stakeholders include: municipalities (Den Haag, Rotterdam), public entities (Rijkswaterstaat), standardisation entities (BIM Loket, Geonovum), research institutes (TU Delft, TU Eindhoven). 3

Finally, the "Smart data integration for urban applications" project is ongoing, involving the Amsterdam Institute of Advanced Metropolitan Solutions (AMS), TUDelft, Municipality of Almere (FLORIADE site), with the aim to integrate information (GeoBIM included) to support urban applications. 4

4.1.2 France Various French municipalities (e.g. Brest Métropole, Rennes Métropole, Lille Metropole) are collaborating to improve the building permit rules through digitalization and harmonization of Local Urban Planning Plans and Rules (PLUs), under the coordination of CNIG (Conseil National de l'Information Géographique5), with the contribution of IGN (the French NMCA: Institut Géographique National). Additionally, IGN has developed for the Ministry the National Urbanism Geoportal (GPU) whose aim is to facilitate the access to urban and public legal easement documents (using 2D data), for citizens and professionals. To gain legal status, from 2020, documents (including PLUs) will have to be published on Urbanism Geoportal (GPU6). (presently covering a limited number of cities).

As a correlated activity, IGN has submitted a CityGML profile specification (called REF3DNAT) to CNIG (Conseil national de l'information géographique) to serve as an input for the definition of the 3D urban geodata standard, with a core capability of exterior modelling, but able to be updated with BIM models from new construction, in coordination with CSTB (Centre Scientifique et Technique du Bâtiment).

IGN is involved in the GeoBIM-related standardization activities in ISO TC211 (including the GeoBIM Technical

\footnotetext{
${ }^{2}$ https://depilotstarter.vng.nl/sites/default/files/project_bestand/rapport_b im verzamelen_verbinden_visualiseren 1.0 0.pdf (16-7-2019)

${ }^{3}$ https://3d.bk.tudelft.nl/projects/geobim/ $\left(16^{\text {th }}\right.$ July 2019)

${ }^{4}$ https://3d.bk.tudelft.nl/projects/smartdi-ams/ (6 $6^{\text {th }}$ July 2019)

${ }^{5} \mathrm{http}: / /$ cnig.gouv.fr/?page id=2732 $\left(15^{\text {th }}\right.$ July 2019$)$

${ }^{6} \mathrm{http}: / /$ www.geoportail-urbanisme.gouv.fr/ ( $15^{\text {th }}$ July 2019)
} 
Report under ISO/TC59/SC13 JWG 14), Open Geospatial Consortium (OGC) in the IDBE (Integrated Data Built Environment, joint working group of the Open Geospatial Consortium (OGC) and buildingSMART international), and in evolution of OGC CityGML and LandInfra standards.

The IGN LASTIG lab has designed and developed SimPLU3D7 which is a set of Open-Source Java libraries for simulating 3D built forms from morphological constraints by optimizing a numerical function. These can be used to investigate the relationship between morphological constraints (for example, stemming from local planning regulations) and forms produced at the neighbourhood or agglomeration scale. The SimPLU3D approach is generic in the sense that it is possible to define its own constraints, optimization functions or types of forms.

This library has been used in particular to model built forms based on constraints from Local Urban Planning Plans (PLU) and allows the following types of questions to be answered:

- What is the maximum amount of housing that can be built on a parcel?

- How will the shape of my neighbourhood evolve if we modify a PLU?

- Can buildings that shade too much on neighbouring parcels be built?

- A simple web demonstrator has been developed to illustrate its interest8.

4.1.3 Sweden Much of the research and development in the GeoBIM field in Sweden is financed and coordinated by the Smart Built Environment program. In this program there is an ongoing project (coordinated by Lantmäteriet, Sweden's NMCA) "Detailed delivery specifications for Geodata-BIM" that aims at defining delivery specifications for BIM-data and geodata between municipalities and the architecture, engineering and construction (AEC) industry, especially in the building permit process. The information flow is partly based on the EuroSDR diagram for permit data exchange (Figure 1 below).

Another national project, coordinated by the Swedish National Board of Housing, Building and Planning Agency, that aims at improving the building permit process through digitalization. Parts of this projects study how a GeoBIM approach can be used for automated rule checking.

4.1.4 Slovenia The University of Ljubljana are involved in the BIM A+ project, whose objective is to offer an advanced education programme on BIM integrated design, construction and operation processes, with a strong focus on the collaborative practices that are the cornerstone of such integration. This project is part of a European project in collaboration with partners in Italy and Portugal.

The e-space project (e-prostor) involves the Slovenian Ministry of Environment and Spatial Planning, and also the Surveying and Mapping Authority to work towards Digitalization of Construction industry, with particular focus on automation of administration procedures. A Construction and building permission workflow is one of the Use Cases being examined.

\footnotetext{
${ }^{7}$ https://simplu3d.github.io/ (15 th July 2019)

${ }^{8} \mathrm{https}: / /$ demo-simplu3d.ign.fr (15 th July 2019)
}

4.1.5 Spain (Catalonia) A project involving the Departments of the Generalitat de Catalunya (the regional government) is looking at the legal mandate: for the use of the government BIM projects for rapid and precise updating of the ICGC (Institut Cartogràfic i Geològic de Catalunya) topographic databases (CT1M on urban areas at 1:1000 and BT5M full coverage at 1:5000).

4.1.6 Finland Various municipalities (Evolta Oy, Solibri Oy, Gravicon Oy, Sova3D Oy, Lehto Group Oy) are collaborating to improve the building permit process through digitalisation, specifically looking at BIMs in building control inspections, setting up a building permit process based on data models and developing a data model based building permit for a block of flats9.

The cities of Helsinki and, Sitowise are examining BIM and GIS as key ingredients for a digital twin10. The municipalities of Sitowise Oy, Vektorio and Skanksa Oy along with the Metropolia University of Applied Sciences are looking at improving the efficiency of various construction processes through GeoBIM including combining 3D models of a building project with cadastral and city data11.

4.1.7 Norway Conveners Sigve Pettersen, BuildingSmart and Morten Borrebæk from Kartverket (the NMCA) are working with an international group (43 members, from 10 countries) to write a technical report that points out standardization challenges related to interoperability in the context of GeoBIM (ISO/TC59/SC13 JWG 14) (IGN France are one of these partners).

The Norwegian Mapping Authority (across multiple internal divisions) is also working on a study and report relating to how GeoBIM can be used within the authority, to underpin a BIM strategy for the organisation. In parallel with this, they are looking at how BIM can be used within a cadastral context and to update the topographic mapping database.

4.1.8 Ireland Dublin recently held a 3D Data Hackathon with the aim to increase the public use of open BIM and related datasets, including GeoBIM, and seeking new solutions, applications and services addressing four challenge areas: Transportation, Mobility \& Environment, Urban Planning \& Digital Construction, City, Infrastructure \& Asset Use and Civic Engagement \& Serious Gaming. Use cases examined related to a wide range of topics including geoBIM and planning and the event was held in partnership with Dublin City Council and the GrangeGorman Development agency (amongst others) 12 .

4.1.9 United Kingdom $\mathrm{In}$ the wider planning context, The London Borough of Hackney is working with Snook to develop a simplified online planning permit application process with a wizard based approach, with the aim to overcome the issue that $61 \%$ percent of planning applications submitted to Hackney are invalid due to missing fees or

\footnotetext{
${ }^{9}$ http://www.kiradigi.fi/en/experiments/ongoing-projects/bims-inbuilding-control-inspections.html ( $15^{\text {th }}$ July 2019$)$

$10 \mathrm{http}: / / w w w . k i r a d i g i . f i / e n / e x p e r i m e n t s / o n g o i n g-p r o j e c t s / k a l a s a t a m a-$ digital-twins.html (15th July 2019)

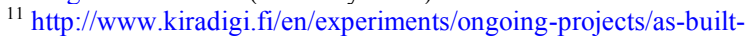
model-using-photogrammetry-and-laser-scanning.html (15th July 2019)

${ }^{12} \mathrm{https}: / /$ smartdublin.ie/unleash-the-power-of-3d-data-for-dublin/ and https://3ddatahack.ie/category/news/ ( $15^{\text {th }}$ July 2019)
} 
missing or incomplete documents. While at this stage BIM submissions are not considered (PDF documents are still required) this approach opens the door to further digital submissions in future 13.

In addition, two other initiatives highlight the increasing use of BIM (beyond government contracts) in the country. In relation to the organisation of information for construction works. To assist the process of transitioning from national standards PAS 1192 to the ISO standard ISO 19650, the Centre for Digital Built Britain have released a national transition document which in particular notes the importance of information management in moving towards a digital built Britain, also noting that the ISO 19650 series considers all information whether it is a construction programme, a record of a meeting, a geometrical model or a contract administration certificate14. The Hackitt Review (published following on from the Grenfell Tower Fire in which 72 livers were lost15) recommended the use of BIM as an information management approach for all buildings higher than 10 stories 16.

\subsection{GeoBIM and Planning Permits: Initial workflow}

Table 1 presents a comparison of current and GeoBIM-enabled planning/permit workflows:

\begin{tabular}{|l|l|}
\hline Current Workflow & GeoBIM Workflow \\
\hline $\begin{array}{l}\text { Building designers design } \\
\text { the building in BIM/CAD } \\
\text { software }\end{array}$ & As for current workflow \\
\hline $\begin{array}{l}\text { They export the needed 2D } \\
\text { data for building } \\
\text { permission (with loss of } \\
\text { data from such a rich and } \\
\text { powerful tool as BIM) }\end{array}$ & $\begin{array}{l}\text { Digital design kept in BIM } \\
\text { against any municipal rules } \\
\text { and adapted accordingly or, } \\
\text { even better, modelled } \\
\text { following templates and } \\
\text { constraints directly given } \\
\text { by the municipality }\end{array}$ \\
$\begin{array}{l}\text { Locate some of the 2D } \\
\text { drawings in the city map to } \\
\text { show the context, without a } \\
\text { defined methodology and } \\
\text { with consequent possible } \\
\text { errors and blunders in the } \\
\text { location }\end{array}$ & $\begin{array}{l}\text { Digital design in geo- } \\
\text { referenced BIM through a } \\
\text { lear and controlled } \\
\text { method, inserted in the 3D } \\
\text { city model. }\end{array}$ \\
\hline $\begin{array}{l}\text { The Municipality office } \\
\text { checks the regulations } \\
\text { compliance through a } \\
\text { partial view of the project: } \\
\text { the 2D representations } \\
\text { aided by a report submitted } \\
\text { by the applicant about }\end{array}$ & $\begin{array}{l}\text { Digital design submitted } \\
\text { and the design validated } \\
\text { against urban regulations } \\
\text { automatically where } \\
\text { possible, removing } \\
\text { subjectivity and } \\
\text { inconsistent decision }\end{array}$ \\
\hline
\end{tabular}

${ }^{13} \mathrm{https}: / /$ wearesnook.com/hackney-council-planning-system/ (15 $5^{\text {th }} \mathrm{July}$ 2019)

${ }^{14}$ https://www.cdbb.cam.ac.uk/news/2018AugBSI_ISOTransition (15 ${ }^{\text {th }}$ July 2019)

${ }^{15} \mathrm{http}: / /$ www.bimplus.co.uk/news/hackitt-review-demands-bimmandate-high-rise-resid/ (15 $5^{\text {th }}$ July 2019$)$

${ }^{16} \mathrm{https}: / /$ www.gov.uk/government/publications/independent-review-ofbuilding-regulations-and-fire-safety-final-report ( $15^{\text {th }}$ July 2019$)$

\begin{tabular}{|l|l|}
\hline $\begin{array}{l}\text { dimensions, technical } \\
\text { details, and so on }\end{array}$ & $\begin{array}{l}\text { making and improving } \\
\text { efficiency }\end{array}$ \\
\hline $\begin{array}{l}\text { After the building is } \\
\text { approved and built, the } \\
\text { existing BIM is no more } \\
\text { used (and potentially lost) } \\
\text { and the city model needs to } \\
\text { be updated through new } \\
\text { the national 3D map, and } \\
\text { also kept for downstream } \\
\text { uses e.g. asset management } \\
\text { checking modelling and }\end{array}$ & \\
\hline
\end{tabular}

Table 1. GeoBIM Links into High Level Planning/Permit Phases

Figure 1 shows a UML diagram representing the workflow of the planning process that we designed. The initial stage takes geospatial data, together with the coded city regulations to be respected, into the BIM to allow for context in any design process. Once the design is complete, it is submitted to the planning authorities, and a cycle of check/adapt/re-check carried out as necessary to validate the formal structure of the model (geometric, semantic and georeferencing validity). After that, the model is used, in integration with the 3D city model, to check the compliance with city regulations in a second check/adapt/re-check cycle. After it's checked, the permit issued and the building built, the final 'as-built' design is submitted for future use and storage. IFC (industry foundation classes, the data exchange standard for BIM) and CityGML (3D data standard for geospatial) are suggested as exchange formats. A more detailed data exchange workflow and diagram can be found in Noardo et al. (2019).

Figure 2 shows a UML Use Case diagram detailing the actors involved at each stage. These include: designers, municipality authorities, building inspectors, GeoBIM data experts, surveyors, the NMCA, urban planners and the applicant themselves (the specific users will vary from country to country).

Within this workflow, the possibility for a generative design process could also be considered: i.e. design where some elements are automated to fit within the specific planning constraints applicable to the site, allowing the rapid generation of automated proposals (e.g. Burry et al., 2018 note the potential applicability of this approach at precinct level).

\section{DISCUSSION AND CONCLUSION}

This paper set out to give a progress update on the EuroSDR GeoBIM project and to present some details about a planning/permits Use Case being developed as part of this project. 


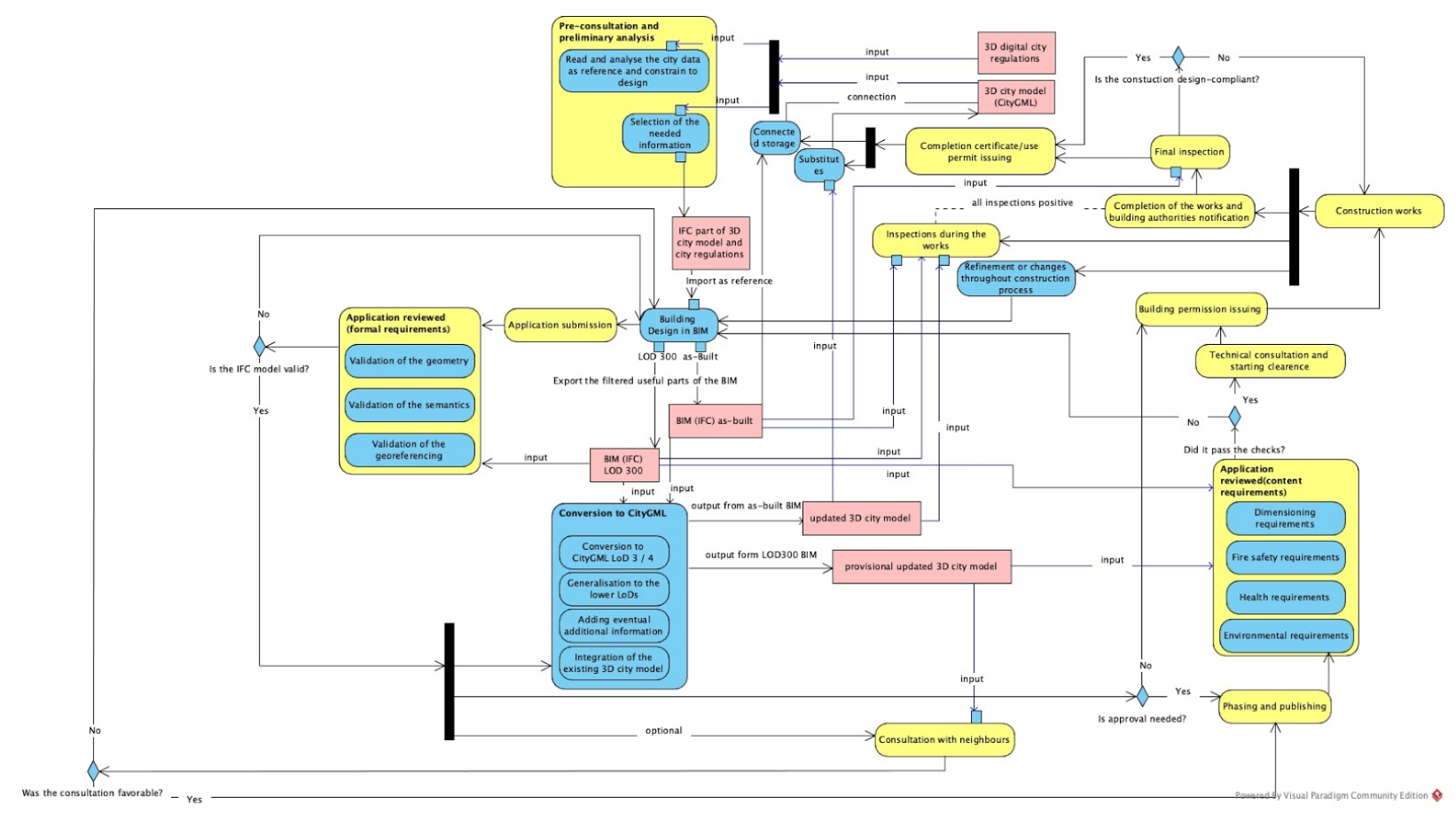

Figure 1 - Integrated Planning Workflow Diagram



Figure 2 - UML Use Case Diagram for the Planning/Permits Workflow 
As can be seen similar to our initial status report in (Ellul et al., 2018) the GeoBIM maturity situation is still very mixed across Europe, although there are increasing signs of GeoBIM activity at national level, particularly in Sweden, The Netherlands, Norway and France. However, it should be noted that the previous report was created as a result of a survey distributed to a wide range of participants, whereas for this update we have only consulted project partners, and thus the projects described are limited by the extent of their personal awareness of such projects.

Our additional work on the planning/permits use case shows that there is indeed potential for this application of GeoBIM and we are now able to identify the actors/users and how they will interact with the workflow, as well as the data exchange points and the specific types of activities (e.g. constraints checks) that can be supported and equally importantly the limits of this process (i.e. checks that cannot be automated).

The work presented in this paper has focussed on planning/permits, and highlights the potential of GeoBIM for pre-construction and construction phases of a building's lifecycle. This work will be followed up by a specific demonstrator. As part of this, IGN with its partner Immobilière 3F (a major social housing company in France) has submitted the BIM model of a social housing project in Epône (78680, Ile de France), and IGN will be providing the geospatial reference data (cadaster units, Urban CityModel CityGML LoD 1, adjacent streets) for this purpose.

Across the wider EuroSDR project, further work will focus on extending the project to the operational phase, with specific focus on the handover from construction to operation (through the means of an 'as-built' model of the building), through the development of an asset management Use Case. This will also include an analysis of data requirements of both BIM and Geo data at every step.

Looking in the other direction, Lau et al. (2018) further note the potential for a geoBIM approach during pre-construction, and in particular the importance of having access to data with regards to the site itself in terms of de-risking the construction process. Coupling these ideas may enable us to move from what Kiavarz et al. (2018) frame as GeoBIM for specific applications in certain fields towards the second approach that they identify: a unified model for a whole lifecycle.

Importantly, the data captured by any GeoBIM process is a fundamental component of any digital twin - as outlined by the Centre for Digital Built Britain's Gemini Principles' Information Value Chain (CDBB 2018, p9). As Batty (2018) notes, a digital twin is not - in reality - an identical twin of the real city, and that abstraction is part of any model creation process. As with any model, the abstraction challenge for GeoBIM is deciding which elements of each phase of modelling should be included in the integrated system, which as in modelling will require an understanding of the end use of the system. The emergence of Model View Definitions which are a subset of the IFC schema for a specific purpose, e.g. for costing a curtain wall or for data archiving (Building Smart 2019), is very relevant to this task. Additionally, this work should also take note of the changes within Building Information Modelling. In particular, the division into PIM (Project Information Model, relating to the delivery phase) and AIM (Asset Information Model, relating to the operation phase) within ISO 19650:2018.

\section{ACKNOWLEDGEMENTS}

The authors would like to thank the participating EuroSDR organisations who are sponsoring this study: 'Agency for Data Supply and Efficiency' Denmark, 'Kadaster' Netherland, 'GUGiK (Head Office of Geodesy and Cartography)' Poland, 'IGN' France, 'ICGC' Catalonia, 'Kartverket' Norway, 'Lantmateriet' Sweden, 'National Land Survey' Finland, 'Ordnance Survey' Ireland, 'Ordnance Survey' UK, 'Swisstopo' Switzerland, 'Geodetski institut Slovenije' and 'Surveying and mapping authority of the republic of Slovenia' Slovenia; and in particular the EuroSDR colleagues from each of these organisations who have contributed to the study design and execution as well as provided comments and feedback on this paper. The input of the participating Academic Institutions has also been fundamental to the success of this project: University College London, UK; Dublin Institute of Technology, Ireland; Lund University, Sweden; University of Ljubljana, Slovenia; and Delft University of Technology, the Netherlands and in particular the participants at the EuroSDR GeoBIM workshop meetings. In addition, we would also like to thank the organisations who have consented to be interviewed as part of this research.

The authors J. Stoter and K. Arroyo Ohori received funding from the European Research Council (ERC) under the European Unions Horizon2020 Research \& Innovation Programme (grant agreement no. 677312 UMnD: Urban modelling in higher dimensions).

\section{REFERENCES}

Arroyo Ohori, K., Diakité, A., Krijnen, T., Ledoux, H. and Stoter, J., 2018. Processing BIM and GIS models in practice: experiences and recommendations from a GeoBIM project in The Netherlands. ISPRS International Journal of GeoInformation, 7(8), p.311.

Batty M, 2018, Digital Twins, Environment and Planning B: Urban Analytics and City Science Vol. 45(5) 817-82

Brasebin M., Perret, J., Mustière, S., Weber, C., 2017, 3D urban data to assess local urban regulation influence, in Computer, Environment and Urban Systems, doi: https://doi.org/10.1016/j.compenvurbsys.2017.10.002

Brasebin, M., Perret J., Reuillon R. 2017b. Stochastic Buildings Generation to Assist in the Design of Right to Build Plans, pp. 373--384, Advances in 3D Geoinformation, Springer International Publishing, doi:10.1007/978-3-31925691-7 21

Burry, M., Karakiewicz, J.A., Holzer, D., White, M., Aschwanden, G.D. and Kvan, T., 2015. BIM-PIM-CIM: The Challenges of Modelling Urban Design Behaviours Between Building and City Scales. Modelling Behaviour (pp. 407-417). Springer, Cham.

Building Smart 2019 - What is an MVD? [online] Available from: https://technical.buildingsmart.org/standards/mvd/ [Accessed 7th July 2019]

CDBB 2018, The Gemini Principles, [available from: ] https://www.cdbb.cam.ac.uk/system/files/documents/TheGemi niPrinciples.pdf [Accessed 7th July 2019] 
Díaz-Vilariño, L., Frías, E., Balado, J. and González-Jorge, H., 2018. Scan Planning and Route Optimization for Control of Execution of As-Designed BIM International Archives of the Photogrammetry, Remote Sensing \& Spatial Information Sciences.

Ellul C., Stoter J., Harrie L., Shariat M., Behan A., Pla A., 2018 Investigating the State of Play of GeoBIM across Europe. In Ken Arroyo Ohori, Anna Labetski, Giorgio Agugiaro, Mila Koeva and Jantien Stoter (eds.), 13th 3D GeoInfo Conference, ISPRS Annals of the Photogrammetry, Remote Sensing and Spatial Information Sciences IV-4(W6)

Hor, A.E., Gunho, S., Claudio, P., Jadidi, M., Afnan, A., 2018. A Semantic Graph Database for BIM-GIS Integrated Information Model for an Intelligent Urban Mobility Web Application. ISPRS Annals of Photogrammetry, Remote Sensing \& Spatial Information Sciences, 4(4).

Kiavarz, H., Jadidi, M., Rajabifard, A. and Sohn, G., 2018. BIM-GIS Oriented Intelligent Knowledge Discovery. International Archives of the Photogrammetry, Remote Sensing \& Spatial Information Sciences.

Lau, S.E.N., Zakaria, R., Aminudin, E., Saar, C.C., Yusof, A. and Wahid, C.M.F.H.C., 2018, April. A Review of Application Building Information Modeling (BIM) During Pre-Construction Stage: Retrospective and Future Directions. In IOP Conference Series: Earth and Environmental Science (Vol. 143, No. 1, p. 012050). IOP Publishing.

Liu, X., Wang, X., Wright, G., Cheng, J., Li, X. and Liu, R., 2017. A state-of-the-art review on the integration of Building Information Modeling (BIM) and Geographic Information System (GIS). ISPRS International Journal of GeoInformation, 6(2), p.53.
Noardo, F., Ellul, C., Harrie, L., Overland, I., Shariat, M., Stoter, J. and Arroyo Ohori, K., 2019. Opportunities and challenges for GeoBIM in Europe: developing a building permits use-case to raise awareness and examine technical interoperability challenges. Journal of Spatial Science, pp.125 .

Oldfield, J., Bergs, R., van Oosterom, P., Krijnen, T.F., Galano, M.M., Lemmen, C., van Oosterom, P. and Fendel, E., 2018. 3D Cadastral Lifecycle: An Information Delivery Manual ISO 29481 for 3D Data Extraction from the Building Permit Application Process.

Olsson, P. O., Axelsson, J., Hooper, M., Harrie, L., 2018. Automation of building permission by integration of BIM and geospatial data. ISPRS International Journal of GeoInformation, 7(8), 307.

Sarafinof, D., Mistre, A., Picinbono, G., Vallet, B., Heydel, L., 2019, La démarche GeoBIM : de la gestion du territoire à celle d'un bâtiment, Responsabilité \& Environnement : Cartographie 4.0 : naviguer avec les cartes du XXIème siècle - Annales des Mines n ${ }^{\circ} 94$ p. 42-46

Sun J., Olsson P.-O. Eriksson H., and Harrie L., 2019. Evaluating the Geometric Aspects of Integrating BIM Data into City Models. Journal of Spatial Science. In print.

Zhu, J., Wright, G., Wang, J., Wang, X., 2018. A critical review of the integration of geographic information system and building information modelling at the data level. ISPRS International Journal of Geo-Information, 7(2), 66. 